\title{
Preparation of gas-tight strontium-doped lanthanum cobaltate by an aqueous sol-gel process
}

\author{
C.H. Chen*, H. Kruidhof, H.J.M. Bouwmeester, A.J. Burggraaf \\ Laboratory of Inorganic Chemistry, Materials Science and Catalysis, Faculty of Chemical Technology, University of Twente, PO Box 217, 7500 \\ AE Enschede, Netherlands
}

Received 15 September 1995

\begin{abstract}
Gas-tight dense membranes of highly $\mathrm{Sr}$-doped $\mathrm{LaCoO}_{3}$ (such as the composition $\mathrm{La}_{0.3} \mathrm{Sr}_{0.7} \mathrm{CoO}_{3}$ chosen in this study) are difficult to prepare using usual synthesis processes. This report presents an aqueous sol-gel route using metal acetates as precursors to achieve this goal. Hydrogen peroxide and ammonia are added to the acetates precursor solution to obtain stable sol and xerogel, as well as a homogeneous powder after heat treatment. Thermal analysis and XRD show the presence of $\mathrm{SrCO}_{3}$ and $\mathrm{La}_{2} \mathrm{O}_{3}$ when the heat treatment temperature of the xerogel is lower than $950{ }^{\circ} \mathrm{C}$. Single phase of cubic perovskite $\mathrm{La}_{0.3} \mathrm{Sr}_{0.7} \mathrm{CoO}_{3}$ can be obtained after treatment at above $1000^{\circ} \mathrm{C}$. Sintering the cold pressed green compact at above $1100{ }^{\circ} \mathrm{C}$ may result in gas-tight samples. It is found that the sintering temperature has a minor influence on the oxygen permeability of a gas-tight membrane.
\end{abstract}

Keywords: Lanthanum cobaltate; Sol-gel; Dense membrane

\section{Introduction}

Perovskite-type $\mathrm{Sr}$-doped $\mathrm{LaCoO}_{3}\left(\mathrm{La}_{1-x} \mathrm{Sr}_{x} \mathrm{CoO}_{3}-\right.$ $\delta$ ) dense membrane is particularly interesting for gas separation owing to its high oxygen ionic conductivity as well as its electronic conductivity. It could be used for the separation of air to obtain pure oxygen and nitrogen-enriched air. In fact, it has been shown that highly Sr-doped $\mathrm{LaCoO}_{3}$ is one of the oxygen semi-permeable materials with the highest oxygen permeability [1]. A good gas-tightness is a critical requirement for the application of such kind of membranes. On the contrary, it is an experimental fact, although the reason is not yet clear, that it becomes more and more difficult to prepare gas-tight and crack-free bulk samples with the increase of Sr content. In our laboratory we have tried various preparation methods, such as mechanically mixing of nitrates and pre-sintering followed by sintering, citrate pyrolysis method, and EDTA method. Most of them, however, have failed to produce gas-

\footnotetext{
* Corresponding author. Present address: Laboratory for Applied Inorganic Chemistry, Delft University ofTechnology, Julianalaan 136, 2628 BL Delft, Netherlands.
}

tight samples as the strontium content $(x)$ is higher than 0.5. Finally, as will be described below, an aqueous sol-gel route is found to be suitable to prepare highly Sr-doped powders and gas-tight bulk samples as well. It is a modification of the method which was used by Bilger et al. [2] to prepare $\mathrm{La}_{0.86} \mathrm{Sr}_{0.14} \mathrm{MnO}_{3}$ powders. In this study, a highly doped composition $\mathrm{Ld}_{0.3} \mathrm{Sr}_{0.7} \mathrm{CoO}_{3}$ is chosen. Oxygen permeation data of a few samples will also be presented.

\section{Experimental}

The flow chart of the synthetic procedure is shown in Fig. 1. Metal acetates $\mathrm{Co}\left(\mathrm{CH}_{3} \mathrm{COO}\right)_{2} \cdot 4 \mathrm{H}_{2} \mathrm{O}(0.2$ mole $)$, $\mathrm{La}\left(\mathrm{CH}_{3} \mathrm{COO}\right)_{3} \cdot x \mathrm{H}_{2} \mathrm{O} \quad(0.06$ mole, $x=0.0083)$ and $\mathrm{Sr}\left(\mathrm{CH}_{3} \mathrm{COO}\right)_{2}$ (0.14 mole) were used as precursors, which were dissolved in $\mathrm{H}_{2} \mathrm{O}(500 \mathrm{ml}$; twice distilled). While stirring the solution, $\mathrm{H}_{2} \mathrm{O}_{2}(153 \mathrm{ml} ; 30 \%)$ was slowly added to it. Foaming as well as solution colour changes (from pink to green) were observed. At last the solution became dark green and clear. Then a small amount of ammonia $(5.3 \mathrm{ml} ; 25 \%)$ was added to peptize the solution into a stable sol. Stirring was constant for 
about $2 \mathrm{~h}$ until no foam was observed. By drying the sol at $80-90{ }^{\circ} \mathrm{C}$ for about $10 \mathrm{~h}$, a homogeneous dark green "resin" or an xerogel was obtained. After heat treatment in an oven at $220^{\circ} \mathrm{C}$ for several hours for drying and the decomposition of some components such as cobalt acetate (see discussion section), the xerogel turned out to be a soft porous product which was then readily crushed into fine powder.

About $40 \mathrm{mg}$ of such powder was taken for a thermal analysis under flowing air $\left(20 \mathrm{ml} \mathrm{min}^{-1}\right)$ by a PL-STA 625 thermal analyzer. The investigated temperature range was from $25^{\circ} \mathrm{C}$ to $1300^{\circ} \mathrm{C}$ with a heating/cooling rate of $10^{\circ} \mathrm{C} \mathrm{min}-1$. The morphology of the powder was observed using an electron scanning microscope (JEOL JSM-35 CF).

Based on the thermal analysis, the powder was calcined for $10 \mathrm{~h}$ at $750^{\circ} \mathrm{C}$. This calcination temperature was chosen in pursuit of a reactive sintering later on. The calcined powder was also heat treated at several temperatures from $900^{\circ} \mathrm{C}$ to $1200^{\circ} \mathrm{C}$ for $5 \mathrm{~h}$ for X-ray diffraction analysis. Step scanning was performed using a Philips PW 1370 diffractometer with $\mathrm{CuK} \alpha$ radiation, over the range of $2 \theta$ from $20^{\circ}$ to $80^{\circ}$ at steps of $0.04^{\circ}$ $(2 \theta)$

The calcined powder was milled in an agate mortar by hand and isostatically cold pressed into green compact pellets ( $16 \mathrm{~mm}$ in diameter) with a pressure of 400 $\mathrm{MPa}$ for $5 \mathrm{~min}$. Each pellet was heated at 950, 1000, $1050,1100,1150$ and $1200^{\circ} \mathrm{C}$ respectively with a heating rate of $180^{\circ} \mathrm{C} \mathrm{h}^{-1}$, sintered at these temperatures for $10 \mathrm{~h}$, and cooled to room temperature at the same

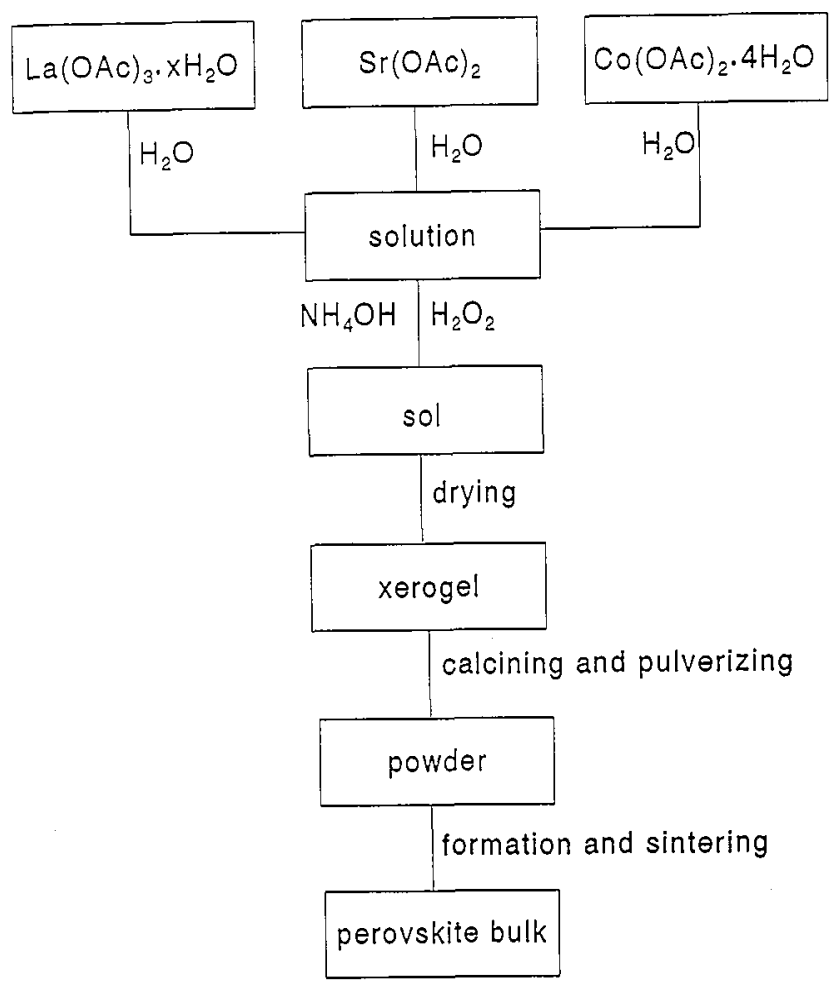

Fig. 1. Sol-gel flow chart for the preparation of $\mathrm{La}_{0.3} \mathrm{Sr}_{0.7} \mathrm{CoO}_{3}$.

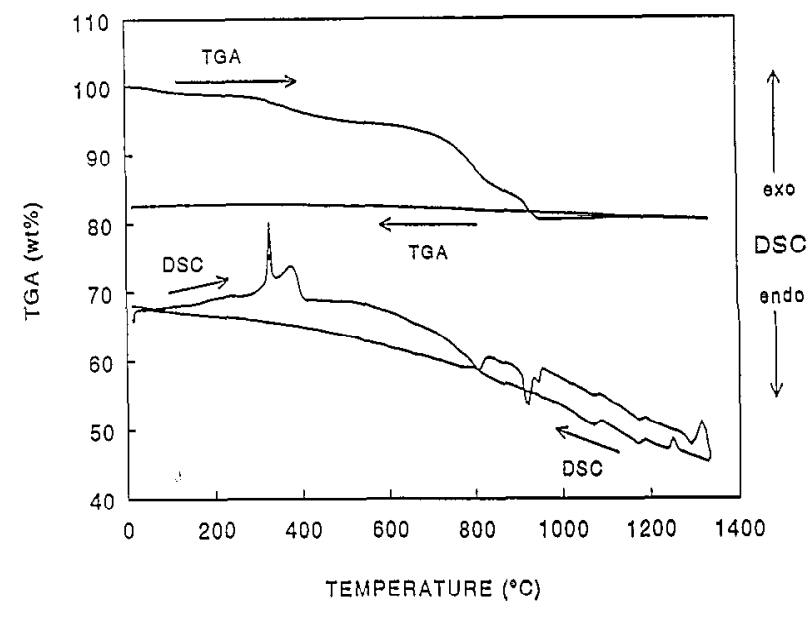

Fig. 2. DSC/TG curves of $\mathrm{La}_{0,3} \mathrm{Sr}_{0.7} \mathrm{CoO}_{3}$ powder (after heat treatment at $220^{\circ} \mathrm{C}$ ).

rate. The sintered pellets shrank to be about $12 \mathrm{~mm}$ in diameter. Densities of the samples were measured by the Archimedes method in mercury. Their gas-tightness was detected by a helium permeation cell at room temperature. By applying a gas pressure difference of about 2 bar across a pellet, helium may diffuse to the other side of a non-gas-tight pellet through microcracks and/or pores. The helium leakage flow rate was used to evaluate the gas-tightness in this study. It should be noted that such a room temperature test only gives a good indication about the gas-tightness of a sample. The decisive evaluation on the gas-tightuess needed to be done gas-chromatographically in a sealed permeation cell at elevated temperatures. The oxygen permeation measurement was conducted in our set-up over the temperature range of $700-1100^{\circ} \mathrm{C}$. The structure and working principle of the set-up have been described elsewhere [3]. The feed side was flushed with air $\left(60 \mathrm{ml} \mathrm{min}^{-1}\right)$ and the permeation side with pure helium $\left(20 \mathrm{ml} \mathrm{min}^{-1}\right)$.

\section{Results and discussion}

With regard to this aqueous sol-gel process, hydrogen peroxide used is found to be very important for the sol and xerogel preparations. Before the addition of hydrogen peroxide, acetates are difficult to be dissolved completely in cold water. However, addition of a small amount of hydrogen peroxide, which serves presumably as a complexation agent, together with other ligands $\left(\mathrm{CH}_{3} \mathrm{COO}^{-}, \mathrm{CO}_{3}^{-}\right)$in the solution, can make the dissolution easily completed. In the course of complexation, the temperature of the solution rose, and $\mathrm{CO}_{2}$ was also detected by gas chromatography. This implies that hydrogen peroxide may also oxidize some acetate groups $\left(\mathrm{CH}_{3} \mathrm{COO}^{-}\right)$to $\mathrm{CO}_{3}^{2-}$ and $\mathrm{CO}_{2}$. The role of ammonia is to make the solution form a stable sol, but an excess of it will lead to precipitation. The sol is 
concentrated during drying, and when the solvent evaporation is nearly finished gelation occurs and a homogeneous xerogel is formed. After calcination, the xerogel is converted to a powder in which the three components are mixed at the molecular level.

Fig. 2 shows the DSC/TG curves of the powder after heat treatment at $220^{\circ} \mathrm{C}$. Naturally, there is not significant thermal effect or mass change occurring below 220 ${ }^{\circ} \mathrm{C}$ except for a small endothermic effect and a small weight loss owing to the desorption of physically adsorbed water. According to the study of Mohamed et al. [4], cobalt acetate has been converted to $\mathrm{CoO}$ after the $220^{\circ} \mathrm{C}$ treatment. Also, the strong sharp exothermic peak at about $300^{\circ} \mathrm{C}$ must correspond to the oxidation of $\mathrm{CoO}$ to form $\mathrm{Co}_{3} \mathrm{O}_{4}$. There follows a lower, broad exothermic peak associated with a small mass loss, but its origin is not quite clear. From $600{ }^{\circ} \mathrm{C}$ to $950{ }^{\circ} \mathrm{C}$ three endothermic peaks are observed, accompanied by a continuous three-step mass-losses. The total mass loss is about 18 wt.\% of the final sample mass of $\mathrm{La}_{0.3} \mathrm{Sr}_{0.7} \mathrm{CoO}_{3}$. It is just in accordance with $0.7 \mathrm{~mol} \mathrm{CO}$ to $1 \mathrm{~mol} \mathrm{La}{ }_{0.3} \mathrm{Sr}_{0.7} \mathrm{CoO}_{3}$. This suggests that the threestep mass loss together with the endothermic peaks probably results from the decomposition of $\mathrm{SrCO}_{3}$ which could be formed during the $220^{\circ} \mathrm{C}$ heat treatment of the xerogel. The presence of $\mathrm{SrCO}_{3}$ below 950 ${ }^{\circ} \mathrm{C}$ has been confirmed by XRD analysis, as will be shown below. The onset decomposition temperature of $\mathrm{SrCO}_{3}$ depends on $\mathrm{CO}_{2}$ partial pressure over the sample, and may be as low as $696{ }^{\circ} \mathrm{C}$ when the $\mathrm{CO}_{2}$ pressure is $0.0335 \mathrm{mmHg}$ [5]. Therefore, the observed decomposition temperature here is reasonable under our experimental conditions. A two-step decomposition of $\mathrm{SrCO}_{3}$ was also observed in $\mathrm{N}_{2}$ flow [6]. It was ascribed to the increase of $\mathrm{CO}_{2}$ pressure during decomposition. Nevertheless, in our case the perovskite phase $\mathrm{La}_{0.3} \mathrm{Sr}_{0.7} \mathrm{CoO}_{3}$ should also be formed in this tempera-

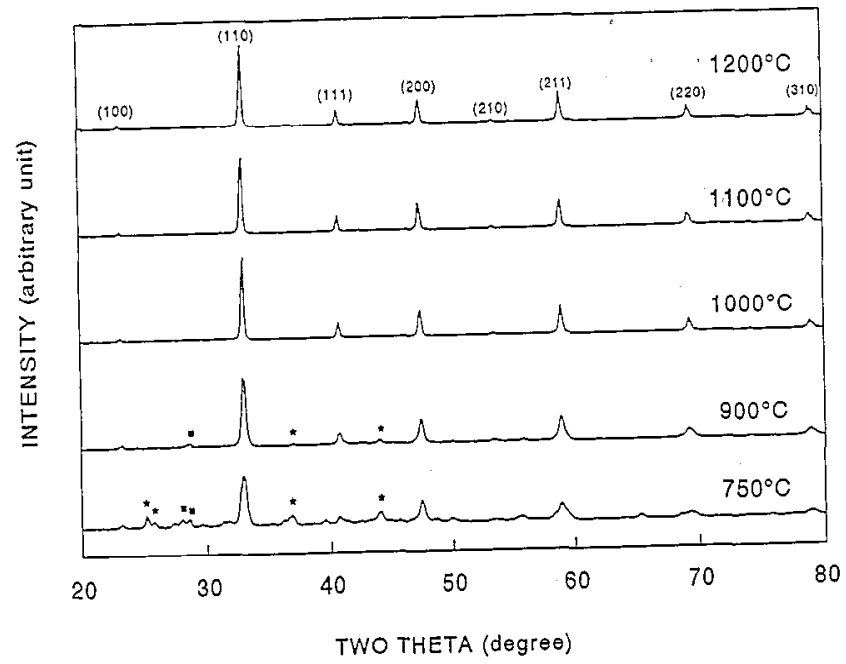

Fig. 3. X-ray powder diffraction patterns of $\mathrm{La}_{0.3} \mathrm{Sr}_{0.7} \mathrm{CoO}_{3}$ powders calcined at differenttemperatures. Asterisks $\left(^{*}\right)$ give the XRD lines of $\mathrm{SrCO}_{3}$, and squares (a) the XRD lines of $\mathrm{La}_{2} \mathrm{O}_{3}$.

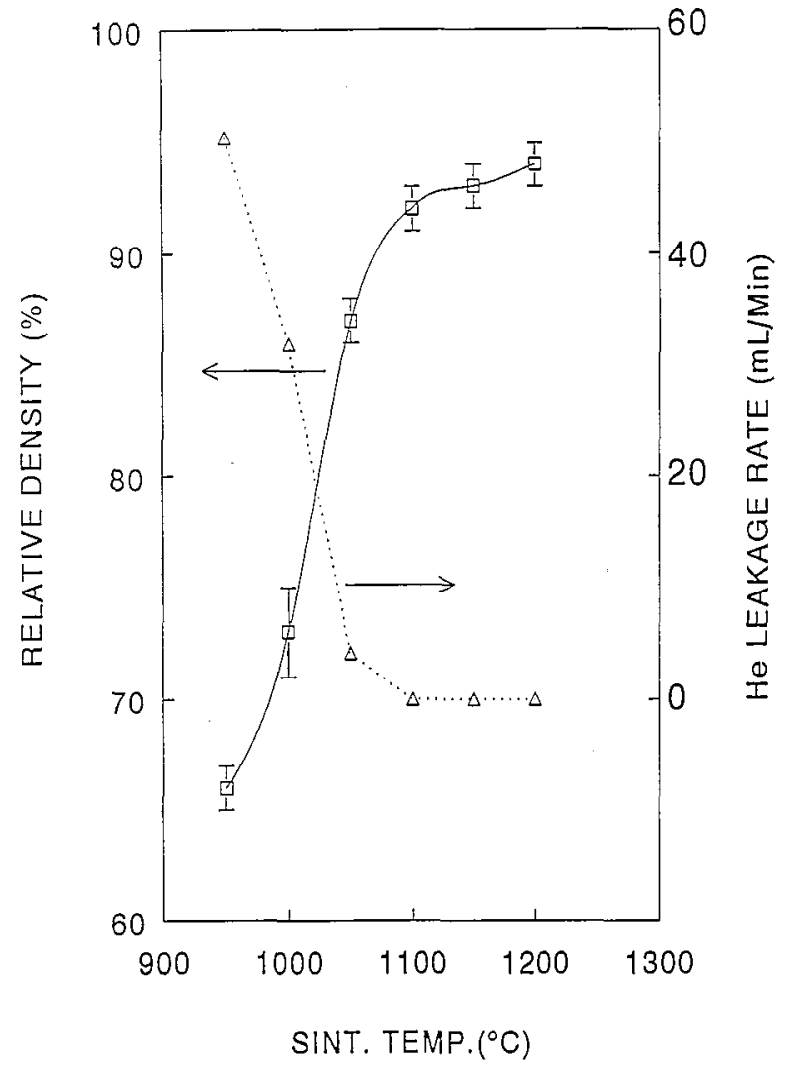

Fig. 4. The relative densities and helium leakage rates of $\mathrm{La}_{0.3} \mathrm{Sr}_{0.7} \mathrm{CoO}_{3}$ pellets sinteredat different temperatures.

ture range because no other thermal (DSC) signals are observed above this range, except for an endothermic peak starting around $1260{ }^{\circ} \mathrm{C}$ which is owing to the melting of the perovskite. In addition, the broad peak appearing just below $400{ }^{\circ} \mathrm{C}$ is believed to be the result of the oxidation of a lanthanum organic compound to form $\mathrm{La}_{2} \mathrm{O}_{3}$, the presence of which has also been confirmed by XRD (see below). On cooling, an exothermic peak in the DSC around $1250^{\circ} \mathrm{C}$ may be ascribed to the solidification of $\mathrm{La}_{0.3} \mathrm{Sr}_{0.7} \mathrm{CoO}_{3}$ melt. The small difference of about $10^{\circ} \mathrm{C}$ is owing to under-cooling in the solidification process. Note that, the apparent thermal effect between $1070{ }^{\circ} \mathrm{C}$ to $1200{ }^{\circ} \mathrm{C}$ originates from $\mathrm{Al}_{2} \mathrm{O}_{3}$ reference for thermal analysis.

The observation by a scanning electron microscope indicates that the powder treated at $220^{\circ} \mathrm{C}$ consists of agglomerates of irregular shapes, and has a broad particle size distribution. This is typical for powders produced by aqueous sol-gel routes, and is also analogous to the powder obtained from citrate pyrolysis. Fig. 3 gives the XRD patterns of the powders heat treated at different temperatures. It can be seen that the powder treated at $750^{\circ} \mathrm{C}$ shows broad XRD lines of the perovskite phase, together with diffraction lines from small amount of $\mathrm{SrCO}_{3}$ and $\mathrm{La}_{2} \mathrm{O}_{3}$. With increasing temperature, the perovskite lines become sharp, and the lines of $\mathrm{SrCO}_{3}$ and $\mathrm{La}_{2} \mathrm{O}_{3}$ gradually disappear at about $1000{ }^{\circ} \mathrm{C}$. Apparently, the decomposition of 


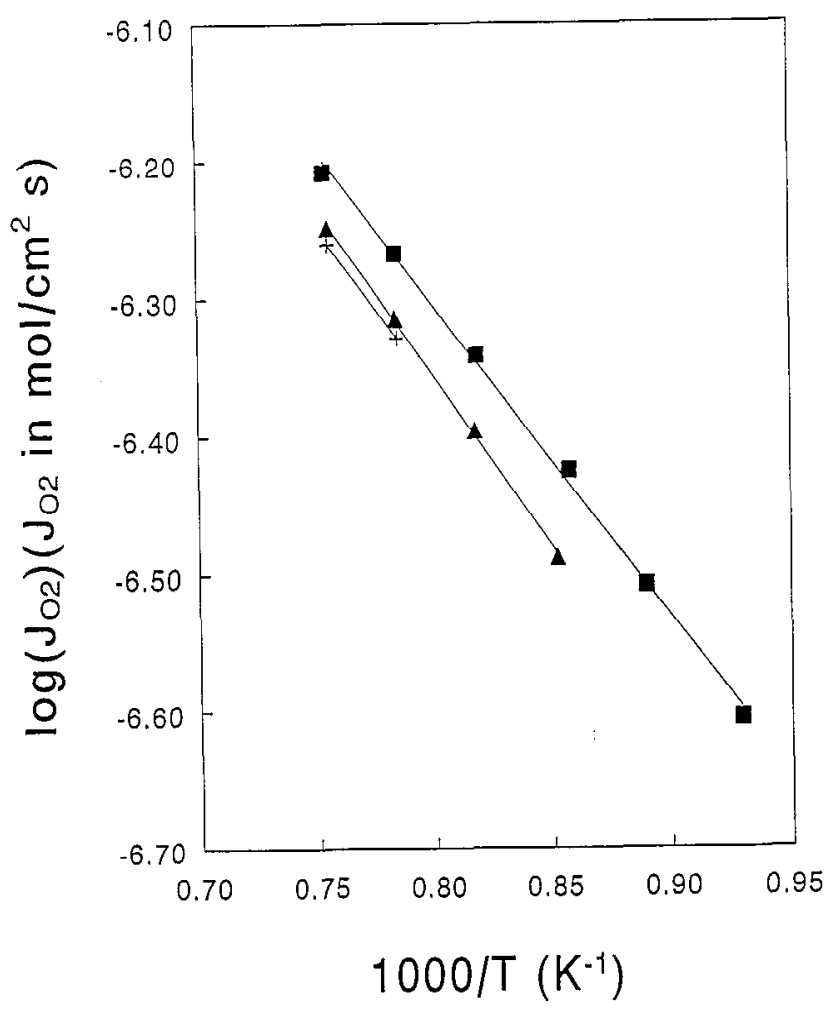

Fig. 5. The temperature dependence of the oxygen permeability of three $\mathrm{La}_{0.3} \mathrm{Sr}_{0.7} \mathrm{CoO}_{3}$ pellets sintered at $1100(\mathbf{0}), 1150(+)$ and 1200 ${ }^{\circ} \mathrm{C}(\mathbf{4})$.

$\mathrm{SrCO}_{3}$ and the completion of the solid state reaction to form $\mathrm{La}_{0.3} \mathrm{Sr}_{0.7} \mathrm{CoO}_{3}$ perovskite phase take place in this temperature range. This is in agreement with the analysis of the DSC/TGA curves. The perovskite patterns can be indexed by a cubic phase, which gives the lattice length of a unit cell $a=b=c=3.84 \AA$, and the theoretical density is therefore determined to be $6.16 \mathrm{~g} \mathrm{~cm}^{-3}$.

The relative densities and helium leakage rates at room temperature for the pellets sintered at different temperatures are given in Fig. 4. It can be seen that the samples sintered at temperatures lower than $1100{ }^{\circ} \mathrm{C}$ are gas-through with relative densities of $67 \%-87 \%$, and cannot be used as dense membranes for producing pure oxygen. The samples sintered at 1100,1150 and $1200{ }^{\circ} \mathrm{C}$ have relative densities of more than $90 \%$, and are gas-tight (at least at room temperature). It has been also found that, after sintering at a temperature higher than $1000{ }^{\circ} \mathrm{C}$, the surface of a $\mathrm{La}_{0.3} \mathrm{Sr}_{0.7} \mathrm{CoO}_{3}$ pellet looks smooth and exhibits a metallic appearance, and some melt traces on the alumina plate uscd as sample susceptor for sintering could be seen. It can be presumed that some extent of liquid phase sintering may occur and lead to a segregation of some component. Increasing oxygen partial pressure in the sintering atmosphere can avoid or reduce the liquid phase sintering. This is worthy of a further investigation.
Fig. 5 shows the temperature dependence of the oxygen permeability (normalized to the feed side area, i.e. $6^{2} \pi \mathrm{mm}^{2}$ ) of three gas-tight pellets sintered at 1100 , 1150 and $1200^{\circ} \mathrm{C}$. Obviously, the measured permeability is quite high, up to $6 \times 10^{-7} \mathrm{~mol} \mathrm{O}_{2} \mathrm{~cm}^{-2} \mathrm{~s}$. Within experimental error, the sintering temperatures between $1100-1200{ }^{\circ} \mathrm{C}$ hardly affect the oxygen permeability. However, samples sintered at 1150 and $1200^{\circ} \mathrm{C}$ sometimes show micro-cracks and are not always completely gas-tight. Therefore, we think that $1100{ }^{\circ} \mathrm{C}$ is the optimal sintering temperature.

\section{Conclusion}

(1) An aqueous sol-gel process has been developed to prepare dense $\mathrm{La}_{0.3} \mathrm{Sr}_{0.7} \mathrm{CoO}_{3}$ ceramics, which can potentially be used as oxygen semipermeable dense membranes for gas separations.

(2) Thermal analysis and XRD have shown that $\mathrm{SrCO}_{3}$ and $\mathrm{La}_{2} \mathrm{O}_{3}$ exists in a powder calcined at low temperatures (lower than $900^{\circ} \mathrm{C}$ ). $\mathrm{SrCO}_{3}$ likely decomposes in the temperature range from 750 to $1000{ }^{\circ} \mathrm{C}$. Single phase of cubic perovskite $\mathrm{La}_{0.3} \mathrm{Sr}_{0.7} \mathrm{CoO}_{3}$ may be formed at a temperature between 1000 to $1200{ }^{\circ} \mathrm{C}$.

(3) Bulk $\mathrm{La}_{0.3} \mathrm{Sr}_{0.7} \mathrm{CoO}_{3}$ is gas-tight when it is sintered between $1100-1200^{\circ} \mathrm{C}$. The oxygen permeability of the samples sintered in this range does not show significant difference.

\section{Acknowledgement}

This work belongs to a collaboration programme between Academia Sinica and Dutch Academy of Science (KNAW) and was financially supported in part by KNAW. Professor Meng Guangyao (Department of Materials Science and Engineering, University of Science and Technology of China) is gratefully acknowledged for stimulating this project.

\section{References}

[1] H.-M. Zhang, Y. Teraoka and N. Yamazoe, Chem. Lett. (1987) 665.

[2] S. Bilger, E. Syskakis, A. Naoumidis and H. Nickel, J. Am. Ceram. Soc., 75 [4] (1992) 964.

[3] H.J.M. Bouwmeester, H. Kruidhof, A.J. Burggraaf and P.J. Gellings, Solid State Ionics, 53-56 (1992) 460.

[4] M.A. Mohamed, S.A. Halawy and M.M. Ebrahim, J. Therm. Anal., 41 (1994) 387.

[5] J.J. Lander, J. Am. Chem. Soc., 73 (1951) 5974.

[6] M.J. Scholten, J. Schoonman, J.V. van Miltenburg and H.A.J. Oonk, Solid State Ionics, 61 (1993) 83. 